\title{
Computational and Experimental Study of Supersonic Nozzle Flow and Aft-Deck Interactions
}

\author{
Walter E. Bruce IV* \\ University of Virginia, Charlottesville, VA 22904, USA \\ Melissa B. Carter ${ }^{\dagger}$ Alaa A. Elmiligui†, and Courtney S. Winski ${ }^{\dagger}$ \\ NASA Langley Research Center, Hampton, VA 23681, USA \\ Sudheer N. Nayani ${ }^{\ddagger}$ \\ Analytical Services \& Materials, Inc., Hampton VA 23666, USA \\ Raymond S. Castner ${ }^{\S}$ \\ NASA Glenn Research Center, Cleveland, OH, 44135 USA
}

\begin{abstract}
NASA has been conducting research into reducing sonic boom and changing FAA regulations to allow for supersonic commercial transport over land in the United States. This particular study looks at a plume passing through a shock generated from an aft deck on a nacelle; the aft deck is meant to represent the trailing edge of a wing. NASA Langley Research Center USM3D CFD code results are compared to the experimental data taken at the NASA Glenn Research Center 1-foot by 1-foot Supersonic Wind Tunnel. This study included examining two turbulence models along with different volume sourcing methods for grid generation. The results show that using the k-epsilon turbulence model within USM3D produced shock signatures that closely follow the experimental data at a variety of nozzle pressure ratio settings.
\end{abstract}

\section{Nomenclature}

$\begin{array}{ll}\text { NPR } & \text { Nozzle Pressure Ratio } \\ \text { GRC } & \text { Glenn Research Center } \\ \mathrm{p} & \text { static pressure, psf } \\ \mathrm{p}_{\infty} & \text { freestream static pressure, psf } \\ \Delta \mathrm{p} & \left(\mathrm{p}-\mathrm{p}_{\infty}\right), \mathrm{psf} \\ \mathrm{R} & \text { Rankine } \\ \mathrm{SWT} & \text { Supersonic Wind Tunnel } \\ \mathrm{x} & \text { distance in the stream-wise direction, inches } \\ \mathrm{z} & \text { distance in the waterline direction, inches }\end{array}$

\section{Introduction}

The High-Speed Project under the NASA Fundamental Aerodynamics Program has made high quality sonic boom prediction with computational fluid dynamics (CFD) a priority. Numerous studies have been

\footnotetext{
*Undergraduate, AIAA Student Member.

$\dagger$ Aerospace Engineer, Configuration Aerodynamics Branch, Mail Stop 499, AIAA Senior Member.

¥Senior Scientist, CFD Group, 107 Research Drive, AIAA Senior Member.

$\S$ Aerospace Engineer, Inlet and Nozzle Branch, 21000 Brookpark Road, AIAA Associate Fellow.
} 
published about supersonic jet plume flow focusing on the accuracy of CFD codes in comparison to the experimental results. These studies have included supersonic jet plume flow ${ }^{1}$ and the interaction of the plume with a wing induced shock wave. ${ }^{2}$ The current study is driven by the idea that an engine placed on top of the wing would impart less noise on the ground due to a shielding effect.

This study focused on the comparison of the NASA Tetrahedral Unstructured Software System (TetrUSS) CFD code USM3D ${ }^{3}$ to the experimental results from the NASA Glenn Research Center 1-foot by 1-foot Supersonic Wind Tunnel (GRC 1x1 SWT) in Cleveland, Ohio in order to determine how well the code can predict the interaction of an aft-deck with supersonic plume flow. The experimental data were collected by a static pressure probe in the tunnel behind the nacelle along with schlieren images that were taken from the windows of the test section. These data points stood as the benchmark in this study while the CFD was run with various turbulence models and grids.

The grid was made by modeling the GRC 1x1 SWT with the nozzle and the aft deck installed in the tunnel test section. Previous studies showed ${ }^{2}$ that by modeling more than just the test section of the wind tunnel resulted in better agreement between experimental and computational data.

\section{Numerical Techniques}

This study exclusively used the TetrUSS code for all of the CFD computations. The CFD package was created and is currently maintained by the NASA Langley Research Center; it includes a geometry setup tool, GridTool, an unstructured grid generation program, VGRID, a grid post-processor, POSTGRID, and the flow solver, USM3D. ${ }^{3}$

\section{A. CFD Code Specifications}

The USM3D code $^{4}$ is a cell-centered, finite-volume Navier-Stokes flow solver that uses multiple flux splitting schemes including Roe's flux-difference splitting scheme ${ }^{5}$ to compute inviscid flux quantities across the faces of the tetrahedral cells. Several options for turbulent closure are available: the one-equation Spalart-Allmaras (S-A) model $^{6}$ (with and without a wall function) and several two-equation models, including Menter's Shear Stress Transport (SST) model. ${ }^{7}$ Throughout the study, the minmod limiter was used in order to keep the flow stable and provide consistent results. For the flow solution cases conducted in this study, either the S-A or the k- $\epsilon$ turbulence model with Sarkars compressibility and pressure dilation was used. ${ }^{1,8}$ This variant of $\mathrm{k}-\epsilon$ model was shown to work well for modeling supersonic jets in references 1 and 8 .

\section{B. Grid Generation}

VGRID is a tetrahedral unstructured grid program that can either be run interactively or in a batch mode with grid spacing corresponding to the strength of user-defined sources placed in the domain. The resulting grids are suitable to compute Euler or Navier-Stokes flow solutions. The methodology is based on the Advancing-Front method (AFM) ${ }^{9}$ and the Advancing-Layers method (ALM). ${ }^{10}$ Both techniques are based on marching processes in which tetrahedral cells are grown on an initial triangular boundary mesh and gradually form in the field around the geometry. Once the advancing front process is completed in VGRID, an additional post-processing step is required using POSTGRID to close any open pockets and to improve grid quality.

A new version of VGRID was introduced in $2008^{11}$ with software updates including growth rates and volume sources. Outer boundary sources were no longer required and were replaced with a user specified growth rate of the grid that dictates how the grids grow outward from the surface along with their maximum size. Also, new volume source types became available in VGRID, including spheres, cones, and cylinders. These new sources allowed for users to have greater control over the areas requiring refined grid than previous versions, which only had point and line sources. 


\section{Plume Sourcing}

In order to capture the plume and other flow characteristics properly, it is very important to source the nozzle configurations adequately and appropriately. In order to capture the shear layer, the cell spacing, distribution, and source divergence angle need to be correctly defined. In addition, adequate cell density is needed to accurately capture the core length and the shock structure. A previous study ${ }^{1}$ showed that a series of five cylindrical sources for the nozzle and field provided adequate grid density to capture the jet plume. Line sources are also placed around the entire nozzle lip to enable a smooth start of the shear layer. The cylindrical sources, mentioned previously, were placed to ensure that the nozzle, plume core, and expansion of the shear layer were properly captured. Additional information about this sourcing method can be found in reference 1.

\section{Experimental Testing Component}

The experimental portion of this study was done at the NASA Glenn 1-foot by 1-foot Supersonic Wind Tunnel. The GRC $1 \mathrm{x} 1 \mathrm{SWT}$ is a variable speed tunnel with 11 discrete airspeeds, ranging from Mach 1.3 to Mach 6, and a test section 53.25 inches long with a cross section of 12 inches high by 12.2 inches wide. At Mach 2, the tunnel can obtain unit Reynolds numbers of 1.329 to 13.031 million per foot. ${ }^{12}$

\section{A. Jet Flow Simulator}

The jet flow model that was used to hold the exhaust nozzle had three major parts: the upper plenum, the strut, and the lower plenum (see figure 1). The upper plenum had an outside diameter of 1 inch and an overall length, from nosecone to nozzle lip, of 8.21 inches. The strut, used to support the upper plenum, had a thickness of 0.35 inches and contained nine air passages used to provide pressure to the nozzle. Air supply lines leading to the strut were 0.25 inches in diameter carrying 90 psia air to achieve 20 psia air at the nozzle inlet for test conditions at 50,000 ft altitude. In order to obtain the correct mass flow, choked orifice holes, 0.210 inches in diameter, were placed on top of the strut supply lines. The air to the strut was supplied through the lower plenum of the rig by the centralized 450 psig pressurized air system at the NASA Glenn Research Center.

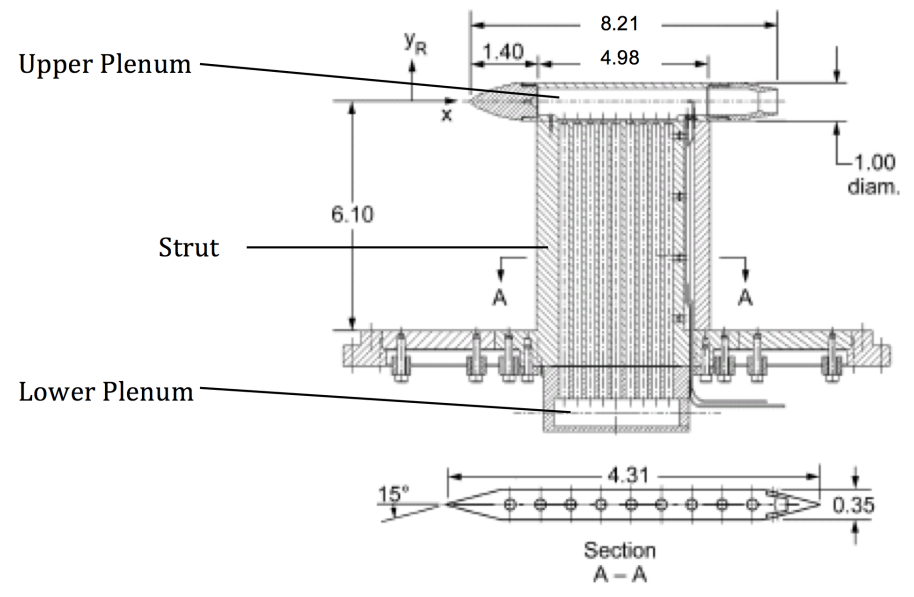

Figure 1. Jet flow simulator cut-away. Dimensions are in inches.

\section{B. Aft Deck and Nacelle Configuration}

Acrylonitrile butadiene styrene (ABS) material was used in conjuction with a 3-D printer to create three nacelle shapes for testing. The nacelles were designed to simulate the outer mold line of a notional propulsion pod and fit over the existing 1 inch diameter upper plenum and nozzle. Additionally, an aft deck that extended 0.65 inches past the nozzle lip was designed and built for testing (see figure 2). 


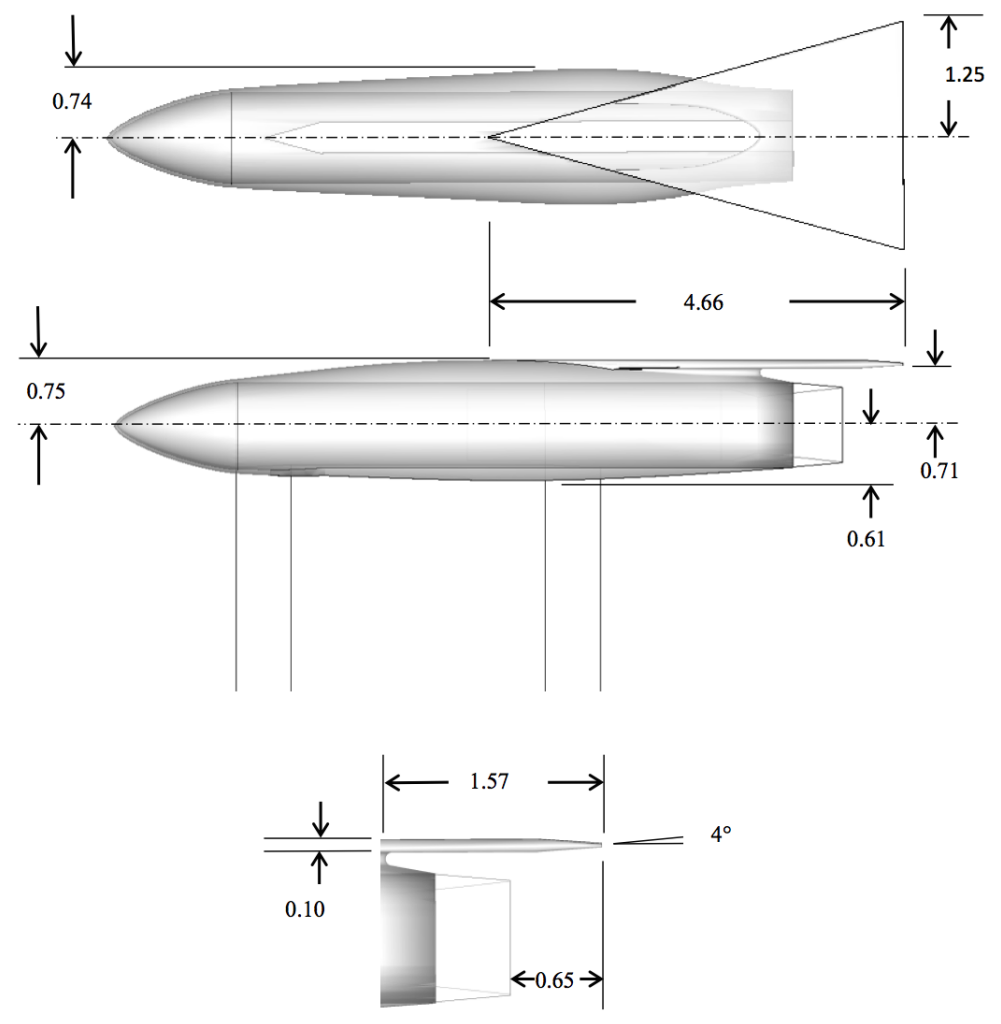

Figure 2. Nacelle with attached aft-deck. Dimensions are in inches.

\section{Data Collection}

For this test, data was obtained at Mach 1.96 with experimental pressures being measured by a probe one nozzle diameter from the centerline on the opposite side of the support strut. The static pressure probe was mounted on an airfoil support connected to a sliding ball screw actuator allowing it to move along the tunnel up to 8.0 inches behind the nozzle. The actuator position and probe starting location were changed during the test, dependent upon where the shock interaction was located. The data were collected 1 nozzle diameter above the centerline with a Pinckney probe due to space restrictions and in order to stay consistent with previous experiments. ${ }^{13}$ The Pinckney probe did, however, exhibit an offset in $\Delta \mathrm{p} / \mathrm{p}_{\infty}$ of -0.08 when tested in an empty tunnel against a standard probe, suggesting an offset in its measurement. For more information on the probe, see reference 2. A diagram of the tunnel set-up can be seen in figure 3 . 


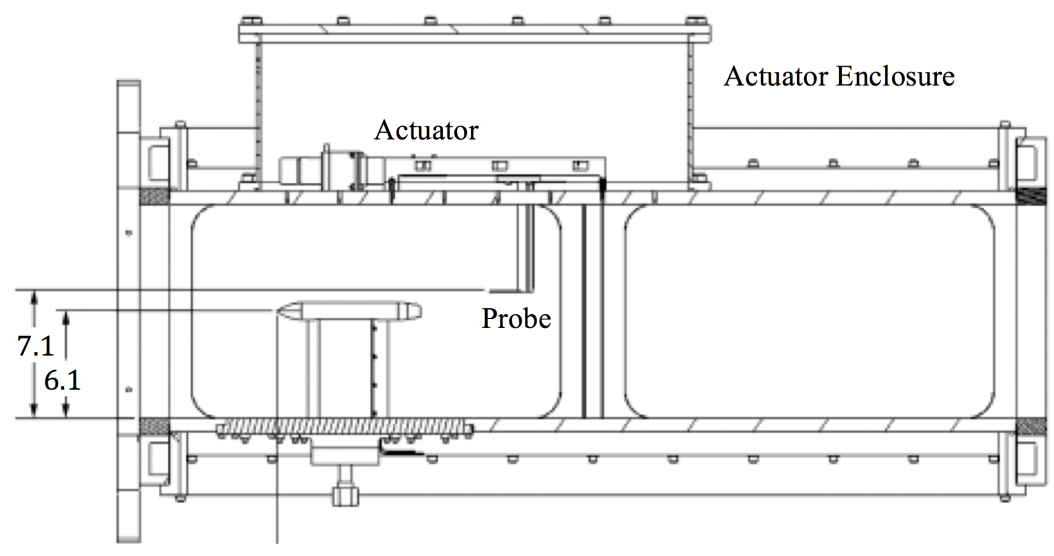

Figure 3. Cross section of the tunnel set-up in the GRC SWT 1x1. Dimensions are in inches.

\section{Results}

All of the USM3D CFD results shown in this section were generated using fully viscous, resolved to the walls grids. The solutions were run until the residual of the L-2 norm reduced by at least 3 orders of magnitude. The simulations were conducted at a freestream Mach number of 1.96, a Reynolds number of 271,526 based on the diameter of the nozzle ( 1 in.), NPRs of $6,8,10,12$, and 14, and a total temperature of $529 \mathrm{R}$.

\section{A. Effects of Turbulence Models}

As part of the early study, an initial grid was run using two turbulence models. The first turbulence model used was the Spalart-Allamaras (S-A) mode, which is a commonly used single equation model. The other turbulence model used was the k- $\epsilon$ (k-epsilon) model with compressibility correction of Sarkar, which as discussed in section IIA has historically provided good results for supersonic jets. It was found that the $\mathrm{k}$-epsilon model had a dampening effect on the expansions in the $\Delta \mathrm{p} / \mathrm{p}_{\infty}$ graph while keeping the first peak fairly similar (see figure 4). The dampening effect on the expansions allowed for a higher second peak, which was more consistent with the experimental data and ultimately made the k-epsilon model a better fit for this study. Consequently, the k-epsilon model results will be shown for the rest of the paper.

As mentioned in section III.C, it appears the experimental data has a $\Delta \mathrm{p} / \mathrm{p}_{\infty}$ offset of 0.08 . Consequently, the experimental data shown has 0.08 added in the y direction.

\section{B. Grid Topology Study}

Currently, best practices exist for using VGRID to create a grid to capture a plume and to create a grid to capture the pressure signature of an aircraft in free air. However, there is still not a consensus for capturing the signature due to a shock/plume interaction while contained within a wind tunnel. Since the walls of the tunnel are modeled, the grid can not be stretched and sheared to best capture the shock details. Fortunately, with the small size of the wind tunnel used for this study and the limited distance in which data could be obtained, artificial dissipation due to the grid is not as great of a concern. However, another issue when modeling a tunnel is the interference of support and structure induced shocks. Consequently, a grid sourcing study was conducted.

Figure 5 shows the different sourcing methods tested. Method 1 used the best practice plume sourcing, and then specified the rest of the grid size by VGRID's built-in options. Method 2 added angled stretched cells in an attempt to capture the shock off the leading edge of the jet structure. The goal for method 3 was to try to better capture any structure or support shocks by having an overall source that covers the entire tunnel then adding an additional source to better capture the shocks from the aft deck. Method 4 refined on method 3 by reducing the size of the source focused on the aft deck. Finally, method 5 was a combination of the other methods. Instead of having a source along the entire tunnel, method 5 used VGRID's built-in 


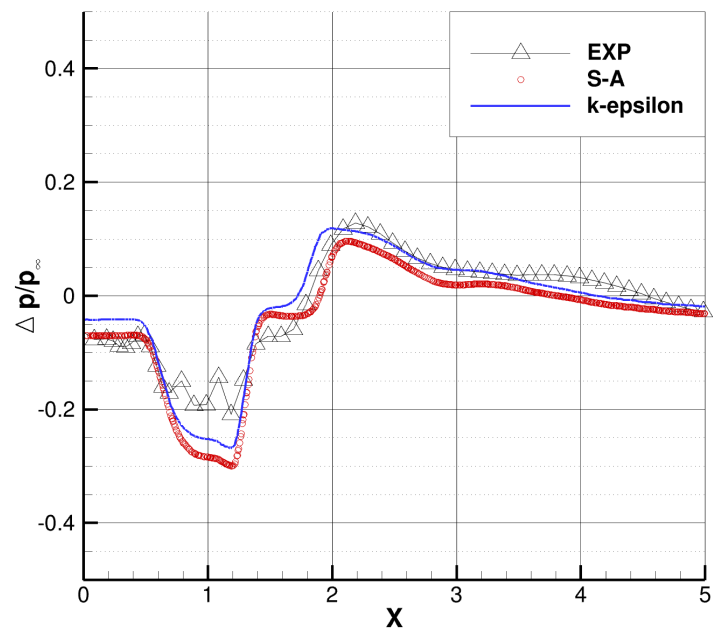

(a) NPR 6

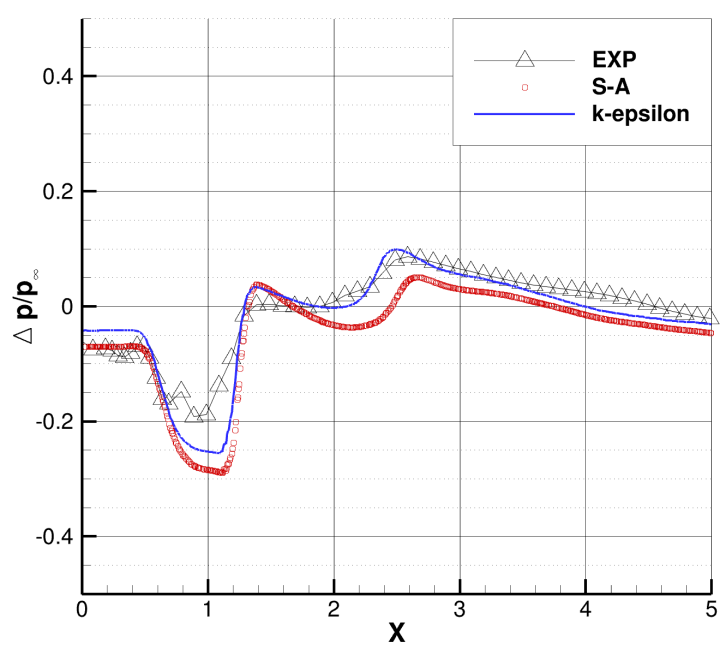

(c) NPR 10

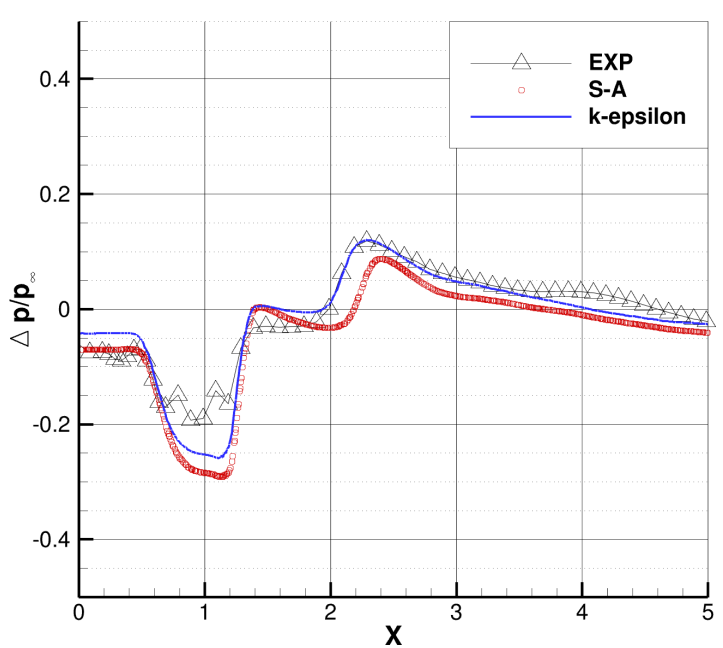

(b) NPR 8

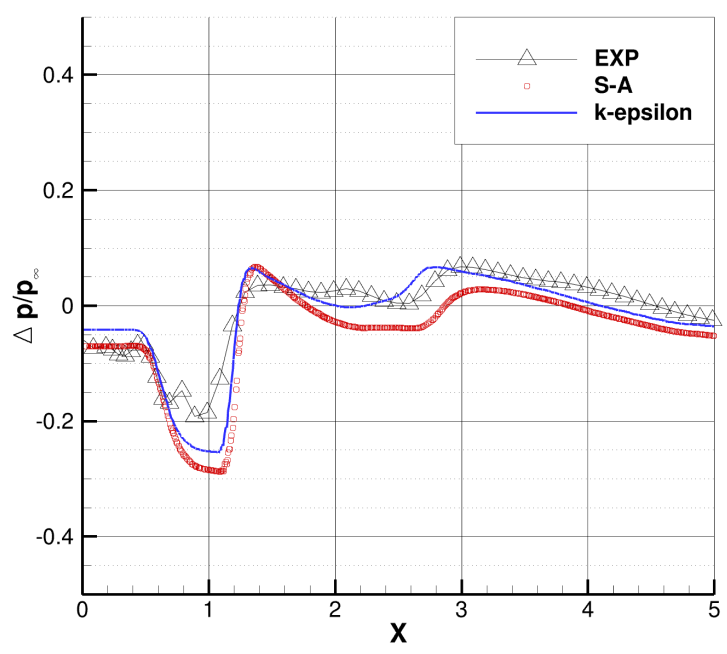

(d) NPR 12

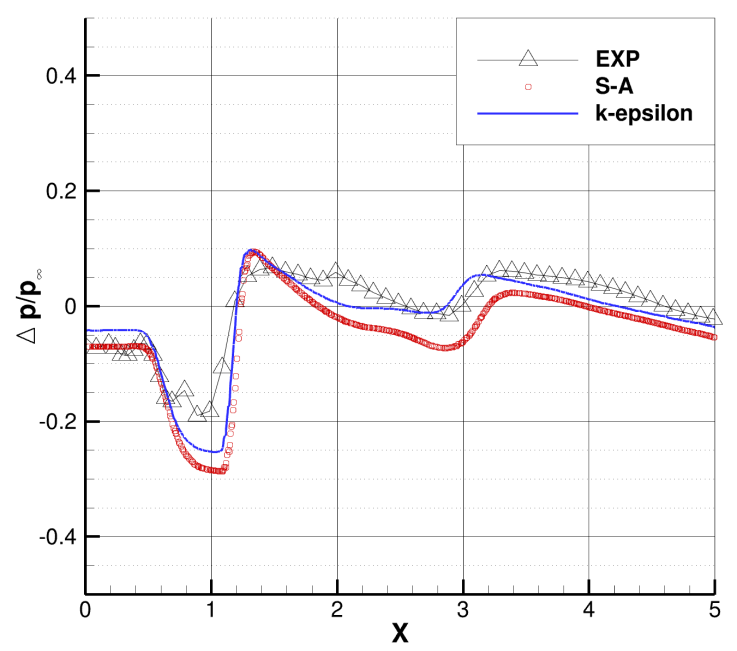

(e) NPR 14

Figure 4. Comparison of the shock signatures from two turbulence models. 


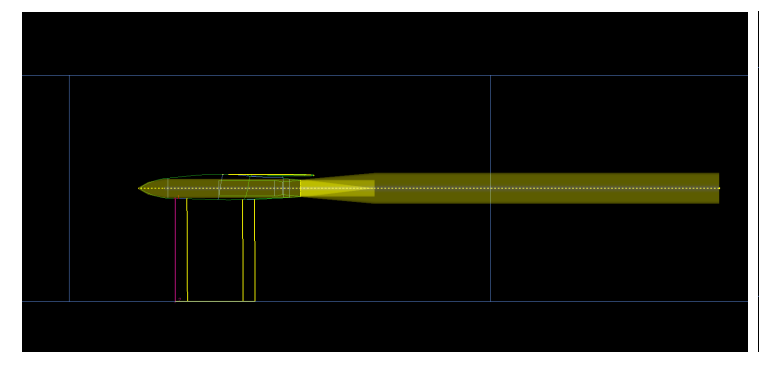

(a) Method 1

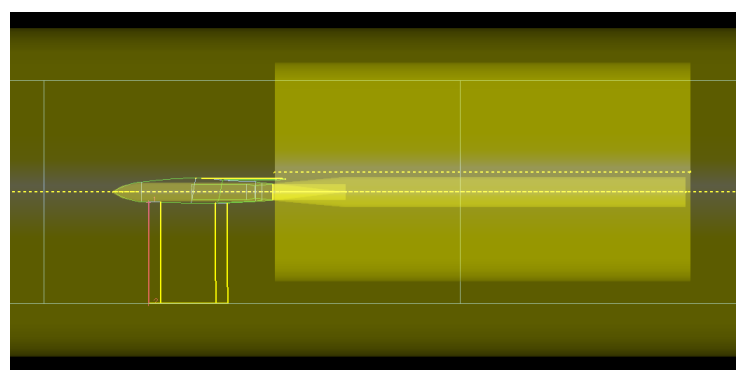

(c) Method 3

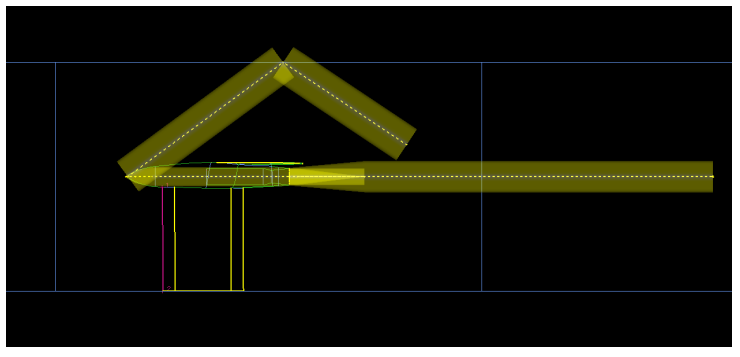

(b) Method 2

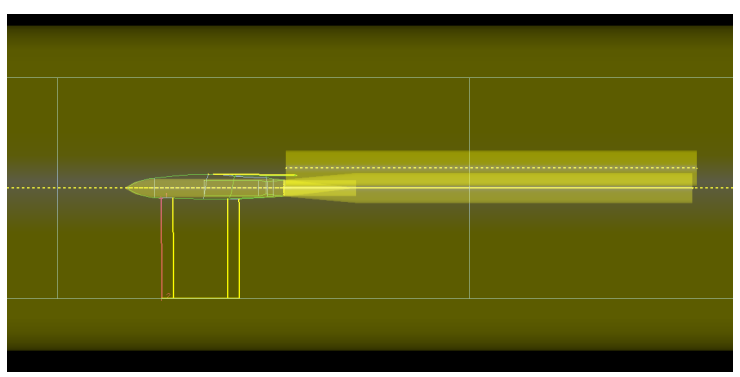

(d) Method 4

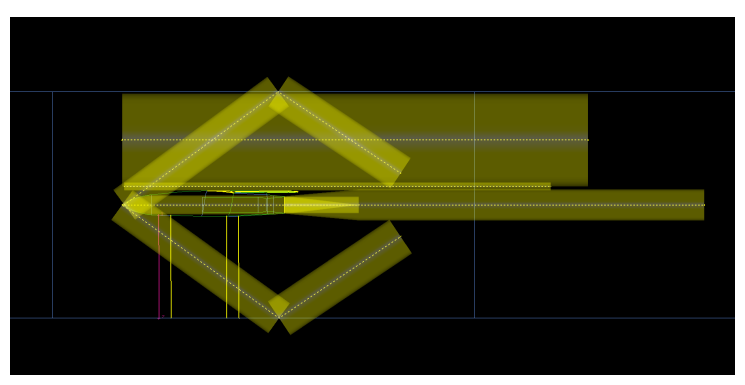

(e) Method 5

Figure 5. Comparison of VGRID sourcing methods. 
options like method 1, the angled and stretched sources from method 2 for both the upper and lower bow shocks (and their reflections) and a combination from methods 3 and 4 to capture the aft-deck source.

Methods 4 and 5 produced the best results, which are compared in figure 6 . Overall the methods 4 and 5 agree, with method 5 consistently predicting a dampened expansion compared to method 4 . Although the effects of the turbulence model study was conducted using method 4 , method 5 results will be shown for the rest of the paper.

\section{Comparison of CFD Results to Experimental Data}

For the data shown in this section, two adjustments were made. As mentioned in section III.C, it appears the experimental data has a $\Delta \mathrm{p} / \mathrm{p}_{\infty}$ offset of 0.08 . Consequently, the experimental data shown has 0.08 added in the $\mathrm{y}$ direction. The CFD data was also shifted to the right in order to match the main peaks, a common practice because of possible discrepancies between the coordinate system of the wind tunnel and that of the CFD simulation.

The previously published ${ }^{13}$ CART3D CFD results for the aft deck configuration are included in the following figures for reference. More details can be found in reference 13 .

Figure 7 compares USM3D and CART3D CFD results to the experimental data for the full NPR sweep. Although USM3D does slightly over predict the expansion and the following shock, the overall signature does closely follow the experimental data. When compared to the CART3D results, USM3D does a significantly better job at predicting both the location and strength of the shocks. Figures 8 through 12 show a comparison between the schlieren images and the computed density gradient. 


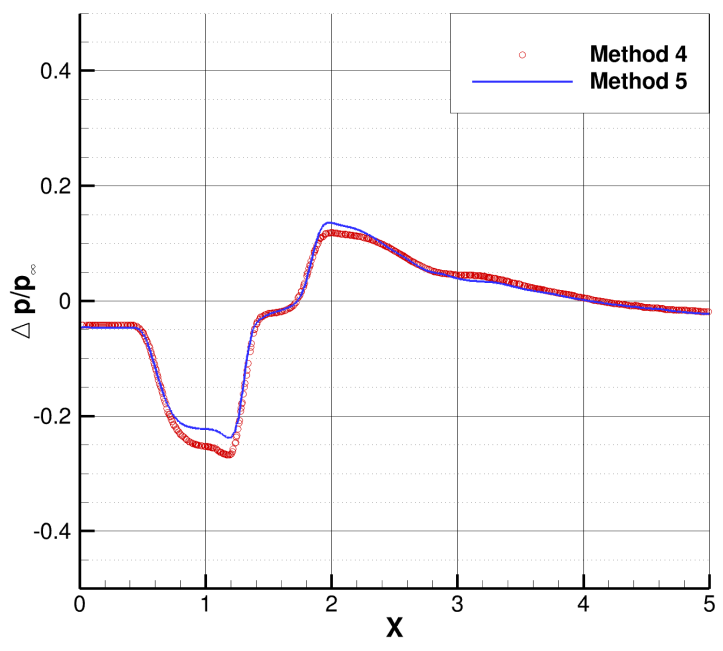

(a) NPR 6

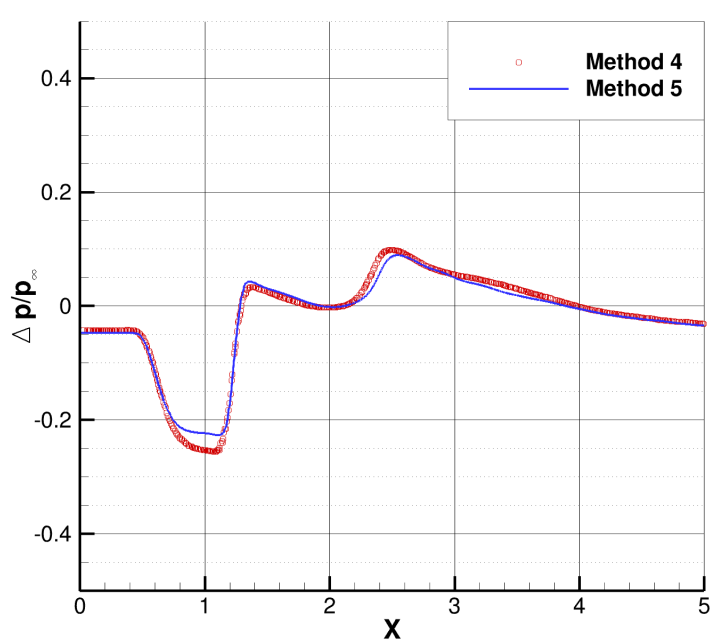

(c) NPR 10

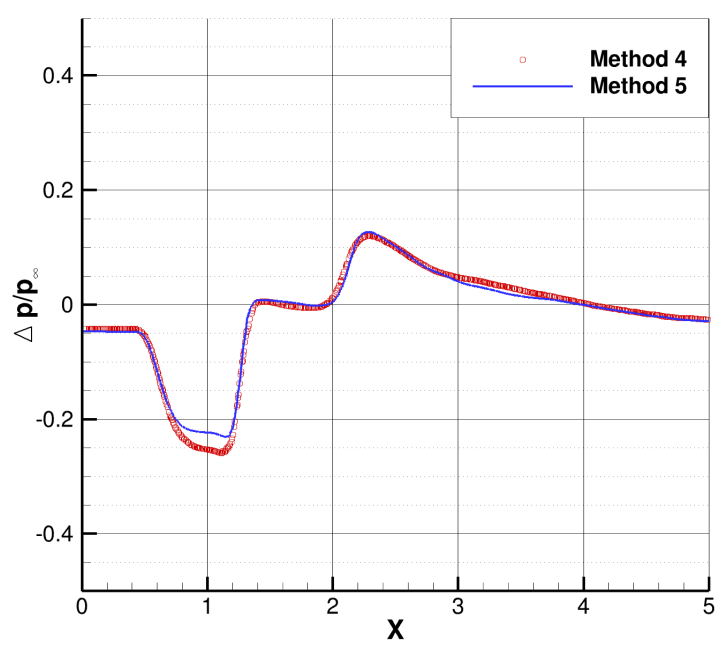

(b) NPR 8

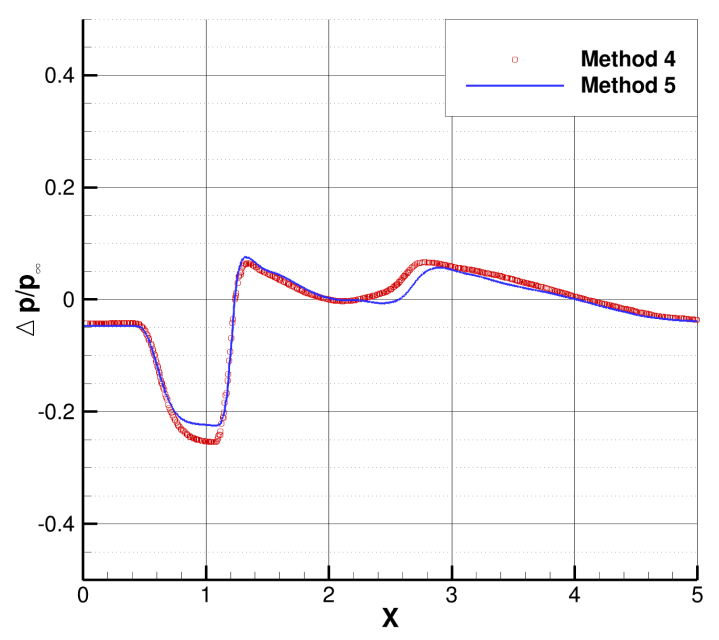

(d) NPR 12

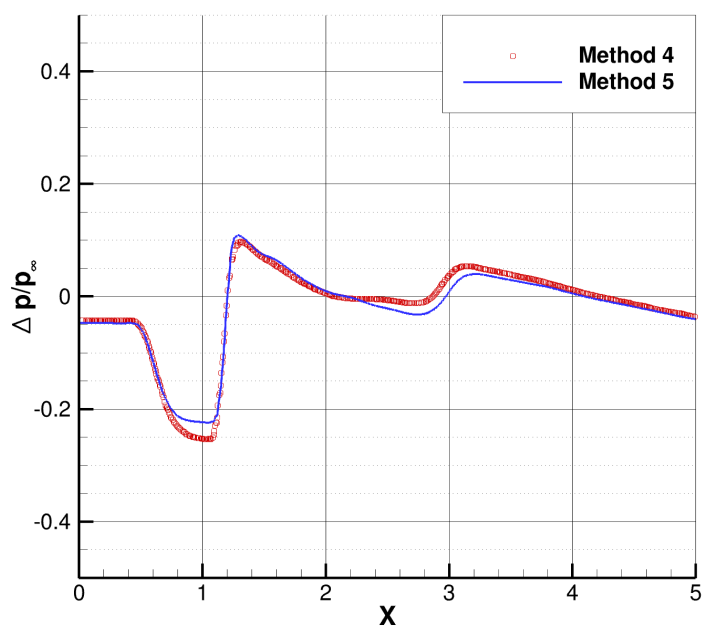

(e) NPR 14

Figure 6. Comparison of the shock signatures from VGRID sourcing methods for various NPR values. 


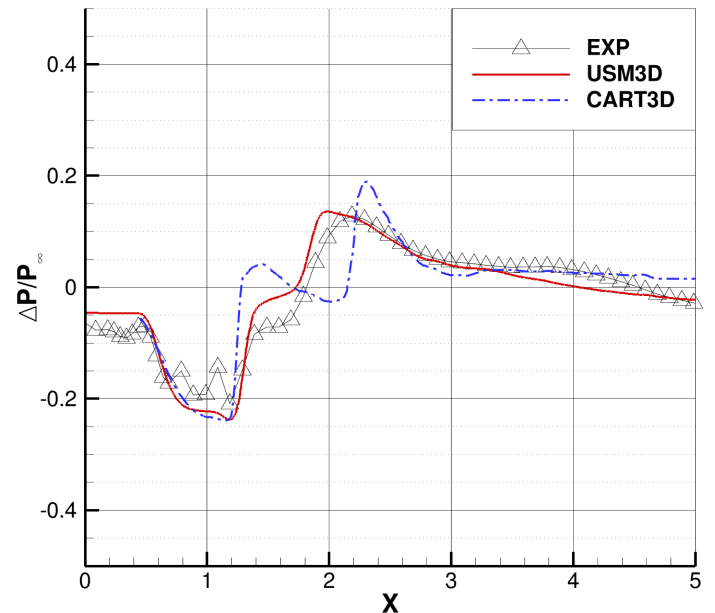

(a) NPR 6

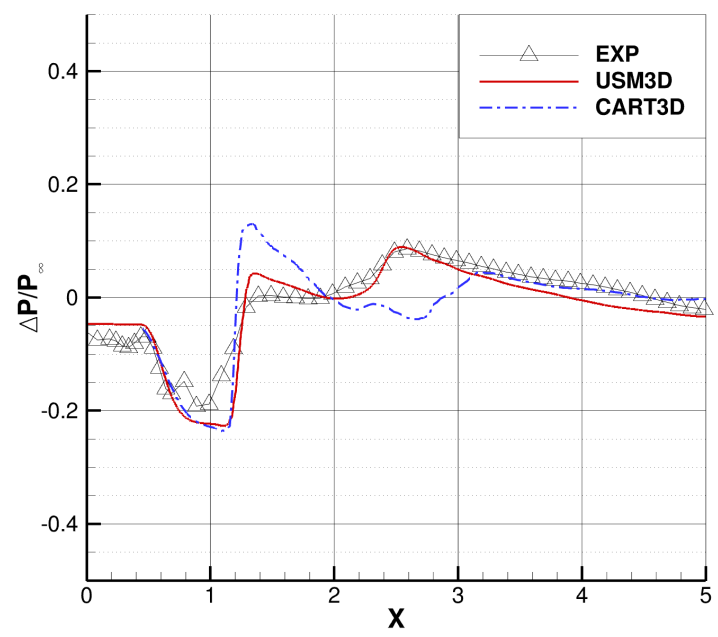

(c) NPR 10

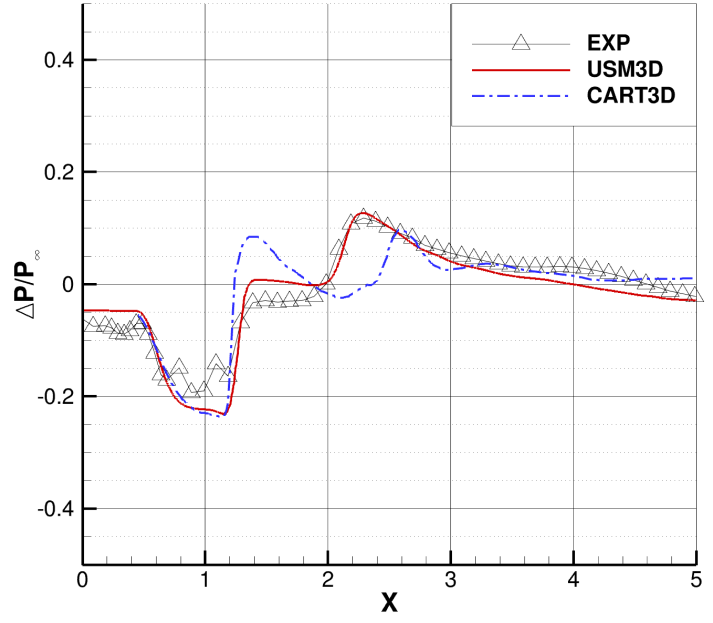

(b) NPR 8

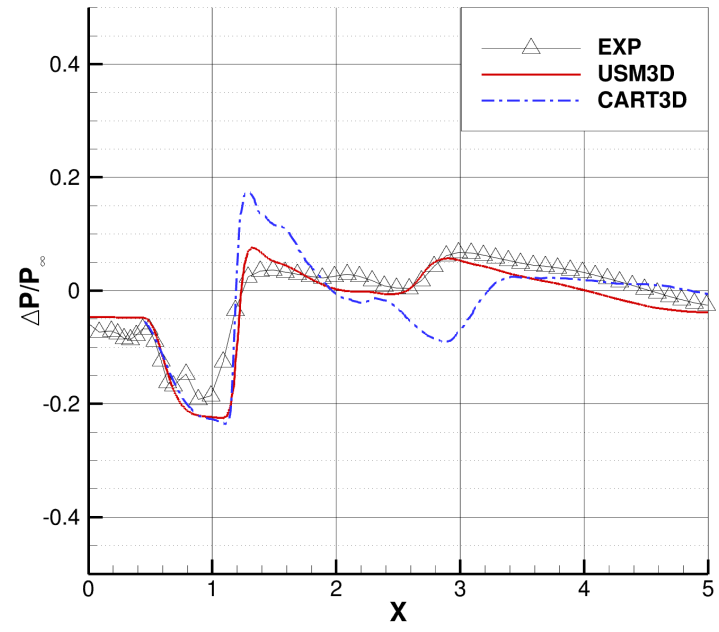

(d) NPR 12

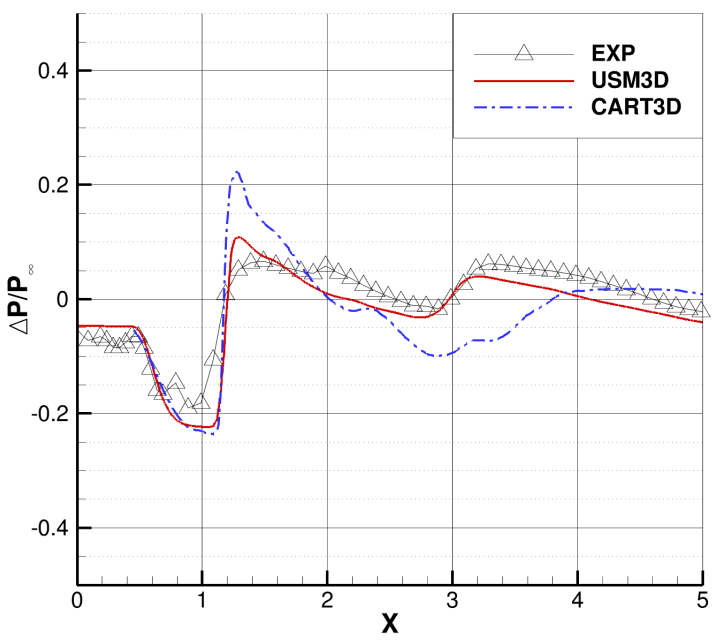

(e) NPR 14

Figure 7. Comparison of USM3D and CART3D CFD results with the experimental data for various NPR values. 


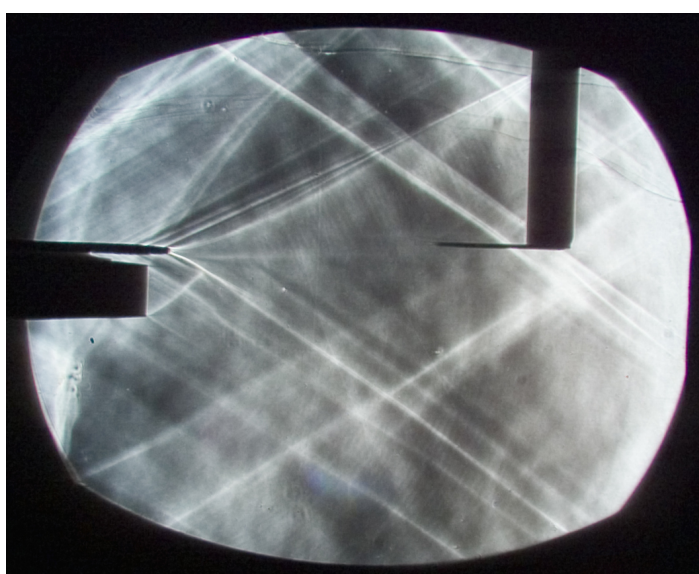

(a) Experimental Schlieren results

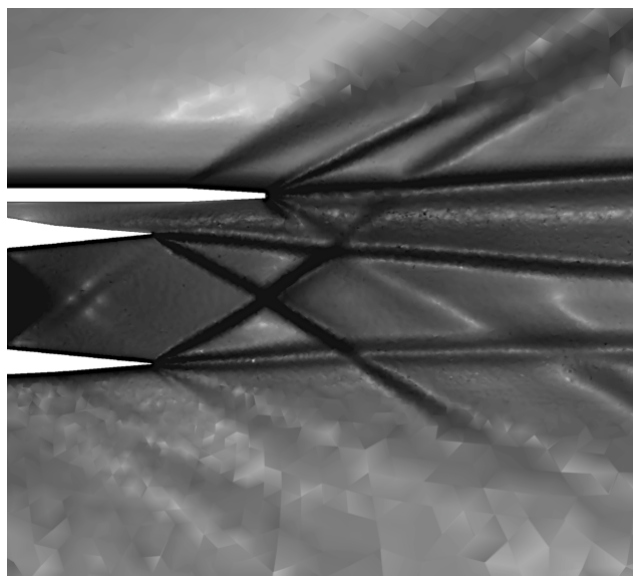

(b) Computational density gradient results

Figure 8. Comparison of the computational and experimental results for an NPR=6

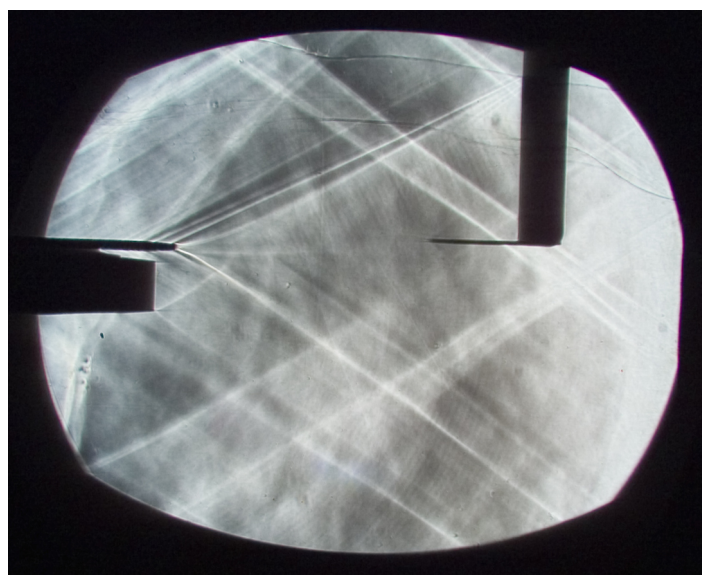

(a) Experimental Schlieren results

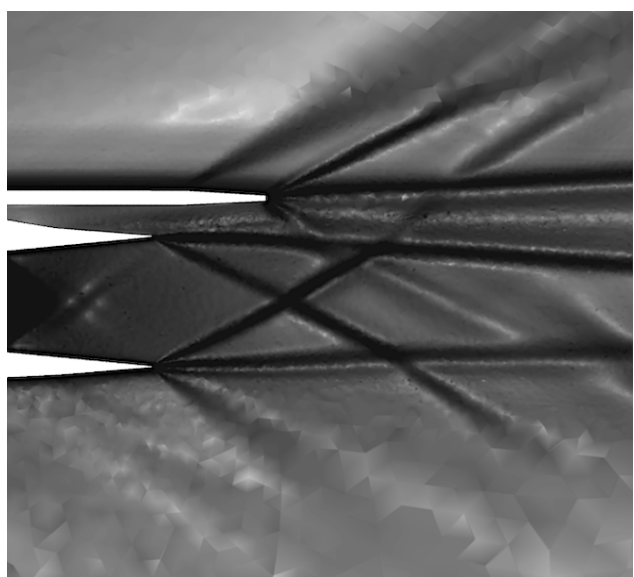

(b) Computational density gradient results

Figure 9. Comparison of the computational and experimental results for an NPR=8

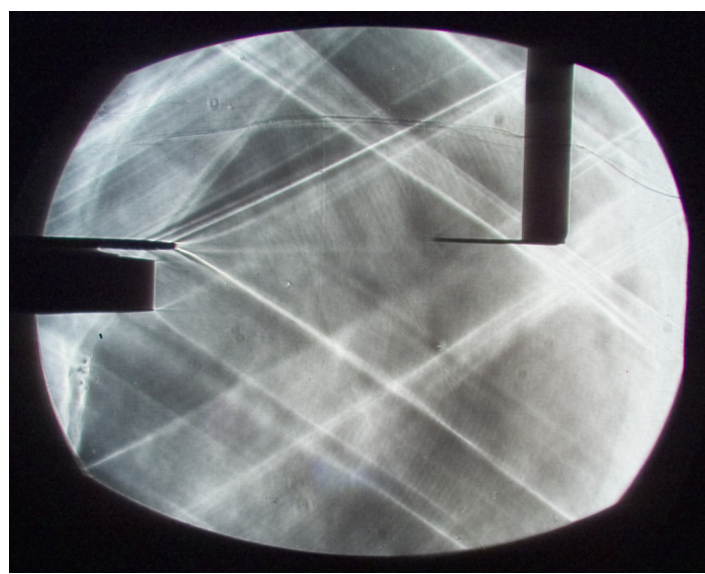

(a) Experimental Schlieren results

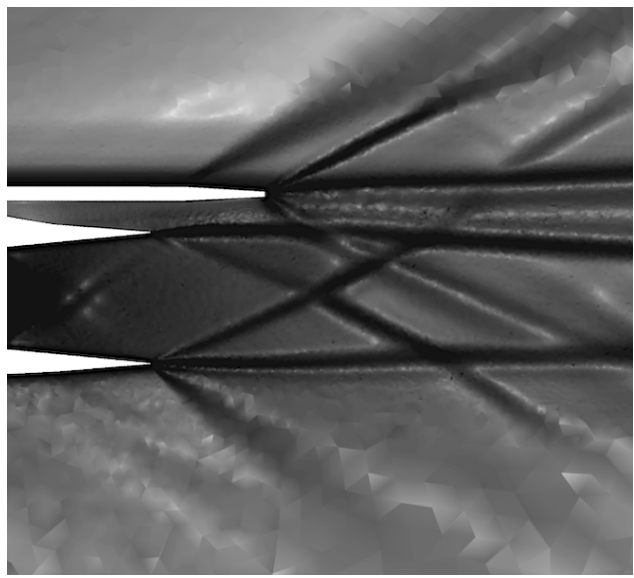

(b) Computational density gradient results

Figure 10. Comparison of the computational and experimental results for an NPR=10 


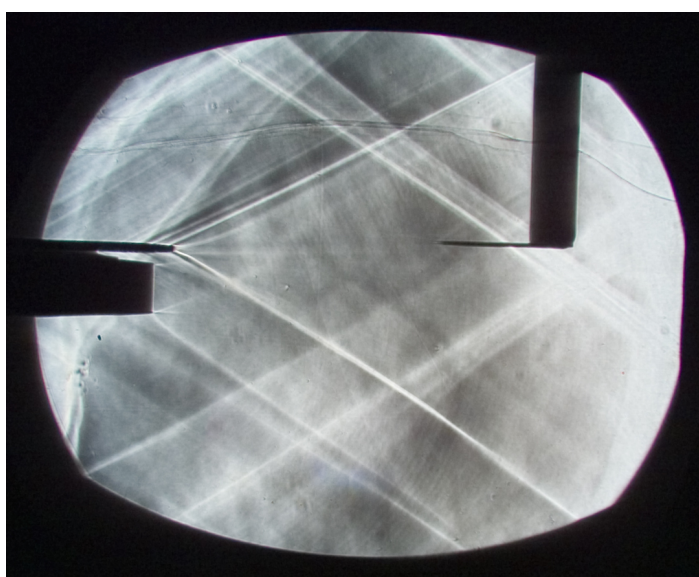

(a) Experimental Schlieren results

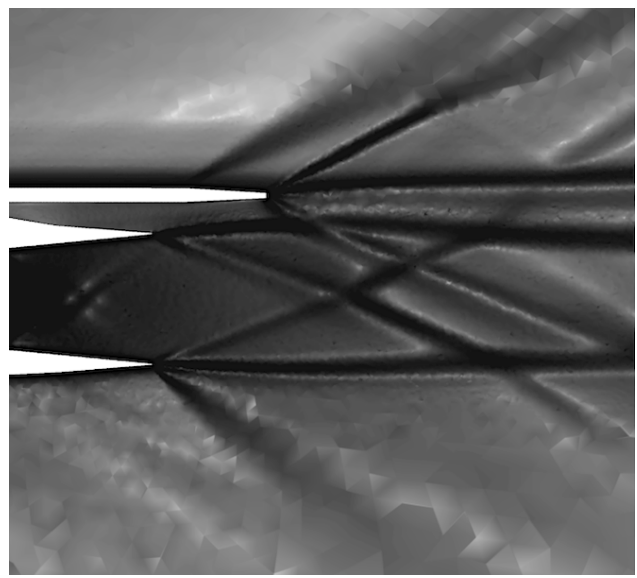

(b) Computational density gradient results

Figure 11. Comparison of the computational and experimental results for an NPR=12

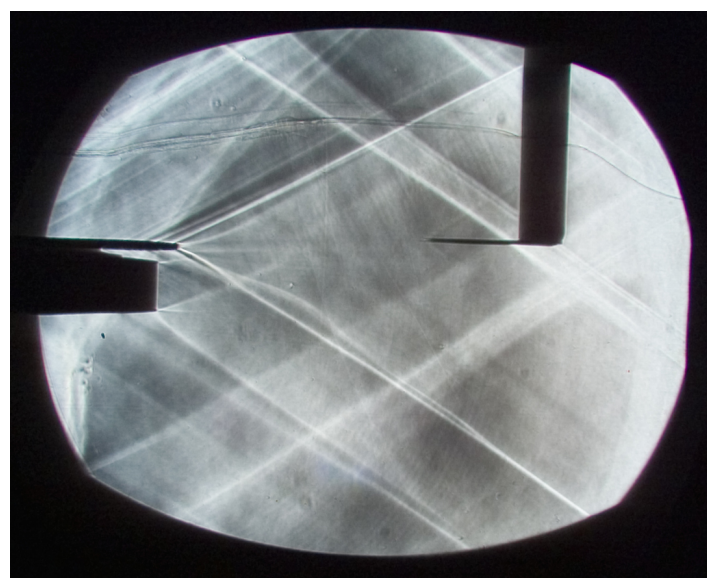

(a) Experimental Schlieren results

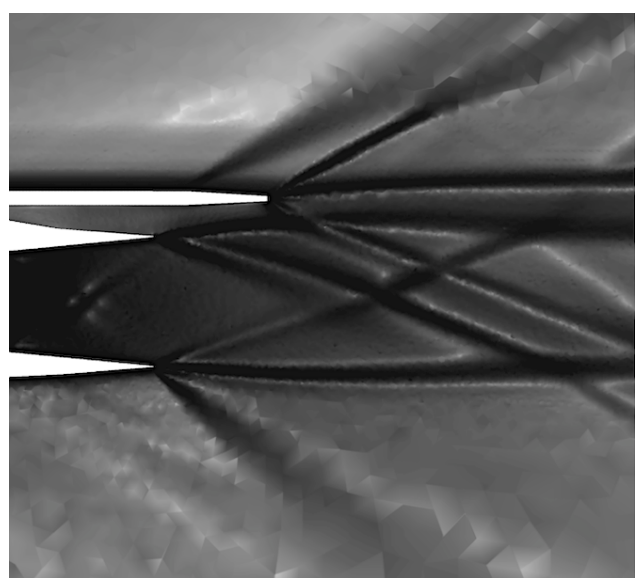

(b) Computational density gradient results

Figure 12. Comparison of the computational and experimental results for an NPR=14 


\section{Concluding Remarks}

This study focused on the interaction between a supersonic nozzle jet flow and shocks emanating from an aft deck shock generator. The CFD simulations done with the NASA flow solver USM3D modeled a wind tunnel test conducted at the GRC 1x1 SWT. Simulations were at a test section Mach number of 1.96 and jet NPRs of $6,8,10,12$, and 14. The turbulence models used in this study were the one equation S-A turbulence model and the two equation k-epsilon model with compressibility correction of Sarkar. Fairly good agreement was observed between the CFD and experimental results.

\section{Acknowledgements}

The research reported in this paper was sponsored by the NASA Fundamental Aeronautics Program Commercial Supersonics Technologies Project.

\section{References}

${ }^{1}$ Carter, M. B., Nayani, S., Elmiligui, A. A., and Campbell, R. L., "USM3D predictions of Supersonic Nozzle Flow," AIAA 2014-2270, 32nd AIAA Applied Aerodynamics Conference, June 2014.

${ }^{2}$ Carter, M. B., Elmiligui, A. A., Nayani, S., Castner, R. S., Bruce, W. E., and Inskeep, J., "Computational and Experimental Study of Supersonic Nozzle Flow and Shock Interactions," AIAA 2015-1044, 53rd AIAA Aerospace Sciences Meeting, January 2015.

${ }^{3}$ Frink, N. T., Pirzadeh, S. Z., Parikh, P. C., Pandya, M. J., and Bhat, M., "The NASA Tetrahedral Unstructured Software System (TetrUSS)," The Aeronautical Journal, Vol. 104, No. 1040, October 2000, pp. 491-499.

${ }^{4}$ Frink, N. T., Three-dimensional upwind scheme for solving the Euler equations on unstructured tetrahedral grids, Ph.D. thesis, Virginia Polytechnic Institue and State University, September 1991. 365 .

${ }^{5}$ Roe, P., "Characteristic-based schemes for the Euler equations," Annual review of fluid mechanics, Vol. 18, 1986, pp. 337-

${ }^{6}$ Spalart, P. and Allmaras, S., "A one-equation turbulence model for aerodynamic flows," AIAA paper 1992-439, 30th Aerospace Sciences Meeting and Exhibit, January 1992.

${ }^{7}$ Menter, F. R., "Improved two-equation k-omega turbulence models for aerodynamic flows," NASA TM-103975, October 1992.

${ }^{8}$ Pandya, M., Abdol-Hamid, K., and Frink, N., "Enhancement of USM3D Unstructured Flow Solver for High-speed HighTemperature Shear Flows," AIAA 2009-1329, 47th AIAA Aerospace Sciences Meeting, January 2009.

${ }^{9}$ Löhner, R. and Parikh, P., "Generation of three-dimensional unstructured grids by the advancing-front method," International Journal for Numerical Methods in Fluids, Vol. 8, 1988, pp. 1135-1149.

${ }^{10}$ Pirzadeh, S., "Three-dimensional unstructured viscous grids by the advancing-layers method," AIAA Journal, Vol. 34, No. 1, January 1996, pp. 43-49.

${ }^{11}$ Pirzadeh, S., "Advanced Unstructured Grid Generation for Complex Aerodynamics Applications," AIAA paper 20087178, 26th AIAA Applied Aerodynamics Conference, August 2008.

${ }^{12}$ Soeder, R. H., Stark, D. E., LEONE, J. F. X., and Henry, M. W., "NASA Glenn 1- by 1-Foot Supersonic Wind Tunnel User Manual," NASA TM-1999-208478/REV1, 2003.

${ }^{13}$ Castner, R., "Exhaust Nozzle Plume Effects on Sonic Boom Test Results for Isolated Nozzles," AIAA paper 2010-4936, 28th AIAA Applied Aerodynamics Conference, June 2010. 